\title{
AMÉRICA ANTE OCCIDENTE
}

Paulo Duarte, el escritor brasileño, al analizar las relaciones entre el Viejo y el Nuevo Mundo hacía referencia a ese equívoco en que caen los europeos al referirse a América. Equivoco que se hace patente en diversas publicaciones en que, en nuestros días, se han reunido las opiniones de los intelectuales europeos sobre la cultura americana. Para la mayoría de estos intelectuales sólo existe una América, la de origen sajón. Sólo se habla de América y como tal se entiende lo que es la América sajona. No se menciona, dice Duarte, "la sensible diferencia que hay entre América y los Estados Unidos de América". "¿Pero cómo olvidar, sin embargo, estos países que estuvieron bajo el dominio de portugueses y españoles...?" A Europa, sigue diciendo Paulo Duarte, le preocupa mucho la orientación de Norteamérica en la pugna que se desarrolla en su interior entre sus ideales de libertad y democracia de los cuales ha sido paladín y el egoísmo materialista que ha permitido su expansión económica sobre el mundo. ¿Qué fuerzas triunfarán en esta lucha? Pues bien, "esta incógnita no angustia solamente a Europa, sino también a una gran parte de la América latina: esa parte del continente que muchos hombres políticos y no pocos hombres dotados de alta cultura, sobre todo en Europa, consideran como una región de salvajes negros, de metecos y de analfabetos". De una manera o de otra Norteamérica es considerada como parte del mundo occidental mientras la América ibera sigue siendo puesta entre paréntesis. Arnold Toynbee, el gran filósofo de la historia, llama a los norteamericanos "occidentales americanos" (American westerners), en cambio la América ibera aparece como parte de los pueblos que habiendo sufrido el impacto de Occidente, reaccionan ahora frente a ese mundo, al igual que la India, China, Rusia y el Africa. “... Hasta la comparativamente débil civilización nativa de México --dice — ha comenzado a reaccionar. La Revolución por la que atraviesa México desde 1910 puede interpretarse como el primer movimiento para sacudir los avíos de civilización occidental que les impusimos en el siglo xvi; y lo que ocurre hoy en México puede suceder mañana en los asientos de la civilización nativa Suramericana: el Perú, Bolivia, Ecuador, Colombia..."

Así, ha sido la cultura occidental la que ha puesto en cuestión la cultura y humanidad del hombre en esta parte de América. Cultura y humanidad puesta entre paréntesis: negada unas veces, otras aceptada pero como algo distinto. Europa y los Estados Unidos han enfocado, en diversas ocasiones, al hombre de esta América y su cultura. Europa viéndolos, en gene- 
ral, como algo inmaduro, acaso como un futuro de cultura muy lejano aún; Norteamérica, como un mundo distinto, acaso como un complemento de su espíritu práctico, acaso como el buscado puente que le permite comprender el mundo oriental. De los europeos, acaso el filósofo que causó más sensación por sus interpretaciones sobre América, fue el Conde de Keyserling. En sus Meditaciones sudamericanas se exponen sus ideas sobre este continente extraño, incomprendido. Para Keyserling, como para muchos otros europeos de los siglos Xv a xIx, la América ibera es un mundo inmaduro, joven, demasiado joven, cosa que ya no sucede con Norteamérica que es ya, en su opinión, de una juventud cercana a la madurez. "Como productos nacionales - dice-, los pueblos de Sudamérica son aún tan jóvenes e incluso tan embrionarios, que sería absurdo criticarlos, tal como es de rigor tratándose de los pueblos viejos de Europa, y ligero partir de una imagen del porvenir, precisa ya en sus contornos principales, como es posible hacerlo en cuanto a Norteamérica". La América ibera tiene un porvenir, pero un porvenir aún más lejano que el de la América sajona. “...Estoy cada vez más convencido de que la humanidad española e hispanoamericana tiene ante sí un magno porvenir. Las posibilidades particulares de la moderna civilización ibérica cuentan entre aquellas cuya realización ha de precisar la humanidad entera en el curso de los próximos siglos. Si al periodo histórico norteamericano no sigue un periodo ibérico, la culpa toda será, única y exclusivamente, de la posible pereza y el posible indiferentismo de los españoles y los hispanoamericanos". Es éste un mundo extraño, telúrico, demasiado natural; en él no ha puesto aún su impronta el hombre. Es un mundo, dice Keyserling, del Tercer Día de la Creación. "El hombre contempla alli, involuntariamente, cara a cara, a la Magna Mater." "El espíritu teme aquí la luz." Keyserling repite en el siglo xx muchas de las opiniones de un Buffon y un De Pauw sobre la América, como continente sin madurez, húmedo, blando, en el que la creación está aún en la etapa de los reptiles. "Toda intelectualidad autóctona es pasiva, e impasibles los rostros. La expresión impenetrable, sorda y ciega, pero al mismo tiempo acechante y preñada de amenazas, que allí muestran muchos más hombres de los que puede haber malvados, refleja la mirada de los anfibios y los reptiles de aquel continente. Hasta el espléndido entusiasmo que a veces estalla con volcánica violencia en el hombre sudamericano, tiene algo de reptil. Semeja el brusco impulso del anaconda real, que después de lanzarse en un salto formidable vuelve en el acto a su entumecida apatía. Y la primera vez que alli encontré hombres de aspiraciones espirituales surgió espontáneamente en mi imaginación... el símbolo primordial mexicano: la serpiente alada."

Este hombre no es propiamente un hombre, puesto que le falta la dimensión del espíritu. Es un proyecto, algo por ser, acaso de una calidad ex- 
traordinaria; pero un hombre que no es aún Hombre, que no posee aún humanidad; es un hombre demasiado pegado a la tierra, más cercano al reptil. Un hombre, que si es hombre, es aun incomprensible para el resto de la humanidad. "Sudamérica - dice Keyserling- me ha dado mucho más que la India y la China. El chino como el indio, me es afín, pues también él vive profundamente por el espíritu; y así lo que de mí le diferencia no alcanza mayor significación de lo que me diferencia a mí de un francés o de un inglés. El sudamericano es total y absolutamente hombre telúrico. Encarna el polo opuesto al hombre condicionado y traspasado por el espiritu." Se trata de hombres en los que la seguridad sigue siendo el problema primordial; hombres a la espectativa, siempre alertas ante un mundo que todavía no ha sido puesto a su servicio. Un mundo en el que la acción del hombre no ha adquirido, todavía, un sentido universal. El hombre no crea, aún, lo espiritual. "Cúando la realidad espiritual llega a ser exclusivamente determinante - dice Keyserling-, el mundo de la gana queda disciplinado, el mundo abismal es mantenido al servicio del bien espiritual. Tal es la significación de la imagen simbólica. Apolo matando a la serpiente Pitón. Y del símbolo de Cristo aplastando la cabeza a la serpiente." Esa expresión máxima del espíritu que toma conciencia de sí mismo, la filosofía, no la encuentra, aún, el filósofo alemán, en esta América. "En Sudamérica -dice-, hasta hoy, sólo en un lugar se ha llegado a la codeterminación por una conciencia verdaderamente metafísica: México. Por consiguiente, la tristeza mexicana es la única que tiene como componente el sentimiento trágico de la vida." Mas hay un pero en esta excepción. El símbolo de este espíritu en México expresado en su religión primitiva, es la serpiente alada. "El animal que se arrastra sobre el vientre y come tierra quiere echar a volar. Pero sólo es capaz de corto vuelo. $\mathrm{Y}$ así, la espiritualidad sudamericana, como fenómeno general, es, hasta el día, semejante al lazo que, una vez lanzado, cae desmayadamente al suelo, $o$ a la serpiente anaconda que se dispara rápida como el rayo para caer en seguida en su apatía incubadora."

\section{II}

José Ortega y Gasset también se preocupó por la América; pero no buscando en ella lo que de común tenía con su España y los anhelos de la misma para occidentalizarse; no se preocupó por la América como filósofo perteneciente a una cultura marginal; sino desde el punto de vista de un europeo, de un occidental moderno. Frente a Europa, Ortega fue un hispano que aspiraba a la incorporación de su mundo en la cultura occidental; frente a la América fue un europeo enjuiciando sus pretensiones para alcanzar la universalidad de su cultura mediante una incorporación semejante a la anhelada 
por él. El filósofo hispano, en función de filósofo europeo, no vio sino lo que los europeos veían en América: inmadurez, "minoría de edad", primitivismo y barbarie. "Como los americanos parecen andar con prisa -dice- para considerarse los amos del mundo, conviene decir: IJóvenes, todavía nol Aún teneis mucho que esperar y mucho más que hacer. El dominio del mundo no se regala ni se hereda. Vosotros habéis hecho por él muy poco aún. En rigor, por el dominio y para el dominio no habéis hecho aún nada. América no ha empezado aun su historia universal." Existen europeos que ven en América un futuro, el futuro de Europa. Ortega no acepta esta tesis: "América, lejos de ser el porvenir, era, en realidad un remoto pasado porque era primitivismo." Porque era lo que había dejado ya de ser Europa. Tanto la América sajona, como la ibera, quedan fuera de la comprensión de Ortega que ve en ambas, acaso más en la primera que la segunda, lo que Hegel había ya visto en el pasado siglo: inmadurez, primitivismo. América es aún mera naturaleza, prehistoria, no tiene aún historia; está por hacerse, como lo que hace de un hombre un hombre es precisamente el no poseer naturaleza, el no estar hecho, el estar haciéndose. La historia, entonces, el hombre americano, resulta ser un proyecto de hombre; le falta aún el espíritu, la conciencia de la historia; porque no puede tener conciencia de algo que aún no ha hecho. Pero hay algo más grave en esta condena que Ortega hace a América, algo que destaca, con gran certeza, el italiano Antonello Gerbi: "Un primitivismo que no es el porvenir, significa en realidad una condena más terrible que todas las de Buffon y de De Pauw. Es un infantilismo orgánico incurable." El americano no sólo no era un hombre, si atendemos a su capacidad para el espíritu que se realiza en la historia, sino que ya no podía serlo: era, pura y simplemente, una estampa estratificada, cosificada, del pasado del europeo, lo que éste había sido, lo primitivo sin posibilidad, sin esa posibilidad que había hecho del europeo un hombre, un hacedor de cultura, un espíritu.

\section{III}

Los pensadores norteamericanos, por su lado, al plantearse el problema del ser del hombre americano y su cultura se tropiezan con la diversidad que existe entre la América sajona y la latina o ibera. Problema que también se plantea a los iberoamericanos al enfrentarse a las mismas cuestiones. Los iberoamericanos ven en la América sajona lo que quisieran ser; los anglosajones, la otra parte de su ser. En la primera etapa de la historia de las ideas de Iberoamérica que se refiere a la de la constitución de sus naciones, una vez que se ha emancipado de España y Portugal, Norteamérica se le presenta como el futuro que ha de ser realizado, mientras España, y con ella toda su herencia cultural, se le presenta como lo que tiene que ser rechazado, 
como lo que ha de negarse como si jamás hubiese sido lo propio. Éste es el sentido de la actitud de los grandes emancipadores mentales de la América ibera: Sarmiento, Bello, Bilbao, Lastarria, José María Luis Mora, Alberdi y otros muchos. La herencia española era el obstáculo que impedia a la América ibera incorporarse a la Modernidad de la cual eran una de sus máximas expresiones los Estados Unidos de Norteamérica. El positivismo fue la filosofía con la cual los iberoamericanos trataron de arrancarse la herencia ibera que consideraban un obstáculo para su incorporación al mundo moderno; un instrumento de su sajonización. Instrumento que a la larga fracasa. Viene entonces otro tipo de reacción: la de defensa frente a la América que ha iníciado su expansión en el mundo, incluyendo su expansión en la América latina. La Norteamérica del destino manifiesto, las discriminaciones y la política del "garrote". La Norteamérica de los grandes negociantes que imponen tiranos en América latina para que cuiden de sus intereses. Ésta es la Norteamérica que simbolizó Rodó en la figura de Calibán, el materialismo, frente a la que se alza la figura de Ariel, encarnada en la América latina, la América de la cultura y el espíritu.

De estas dos Américas habla también el norteamericano Waldo Frank; pero de dos Américas que se hallan, por igual, en la sajona y en la ibera. El materialismo, como el espiritualismo, se encuentra en una América y en la otra. No es privativo de ninguna de ellas. La expansión de Calibán es posible gracias a que éste cuenta con sus equivalentes en la América latina; igualmente Ariel, el espíritu de que hacen gala los iberoamericanos, podrá encontrar sus aliados en la América sajona si los busca. "¡Es tan fácil decir que los Estados Unidos son el enemigo - Norteamérica, el Calibán triunfante-y tan fácil a través de una obsesionada contemplación de nuestras faltas, recluirse en el olvido de la propia insuficiencia!" "Hágase que Hispanoamérica mire al Calibán que tiene dentro; al Calibán que coopera tan alegremente con el Calibán de Norteamérica, con el Calibán de la Gran Bretaña." ¿Por qué es malo, pregunta Waldo Frank, que los iberoamericanos odien a los Estados Unidos? "Porque ello reduce la eficiencia de la América hispana frente a sus propios problemas, que son también nuestros problemas." La ambición, el espíritu de conquista, el materialismo de que se acusa a los Estados Unidos es propio de todos los pueblos, es propio de todos los hombres, en una situación histórica determinada. "... Es el síntoma universal de la disolución de los viejos lazos espirituales del hombre. El hombre disuelto y separado del conjunto en que vive su participación dinámica, da inevitable expresión a alguna fuerza anárquica y disolvente, tal como el poderío capitalista." Es una amenaza al espíritu; pero no es propio de los Estados Unidos, sino que anida ya en todos los pueblos. "Ese sintoma existe en Hispanoamérica, lo mismo que en los Estados Unidos. De otra manera -dice Waldo Frankel capitalismo imperialista no se podría extender." Sólo el espiritu podrá 
combatirlo si sabe unirse en una y en otra América para formar un frente común.

El pensador norteamericano analiza la historia de una y de la otra América y muestra cómo en la América ibera, por una serie de razones igualmente históricas, el espíritu ha prevalecido con mayor fortaleza que en la América sajona. El norteamericano, dice Waldo Frank, sabe el peligro que amenaza al espíritu y se apresta a resistirlo. Sin embargo, agrega, en esa lucha que todo el mundo mantiene o debe mantener contra el materialismo disolvente del espíritu, el grupo norteamericano es uno de los que luchan en situación más difícil. "En ningún país se encuentra este grupo creador más sitiado de peligros. Porque el enemigo está sobre nosotros." Las tentaciones son tremendas: hay "luz, éxito, dinero, reconocimiento. El norteamericano de talento tiene que ser heroico en su voluntad, para resistir a esta corrupción del éxito y tiene que poseer una fuerza heroica para resistirla, para permanecer oscuro, tranquilo dentro de la vida americana, de donde brota la creación". "El norteamericano creador necesita ayuda. Nuestro estado es precario. El alimento que recibimos de la brillante y falleciente Europa es con más frecuencia venenoso que nutritivo." Los iberoamericanos pueden hacer mucho en esa lucha contra el materialismo que niega al espíritu; por eso se dirige a ellos Waldo Frank. "En muchas maneras - dice- vosotros estáis más intactos. Las fuerzas centrífugas aquí no son tan fuertes. Vosotros habéis sido menos zapados por la fea Edad Moderna, menos corrompidos por el falso humanismo y racionalismo. Estáis más cerca del sentido de la vida humana, como drama trágico y divino, pues que estáis más cerca de la Edad Media cristiana, en la que todos los valores de Judea, Grecia, Roma, formaron parte de un organismo cósmico. Tenéis valores, mientras nosotros tenemos entusiasmo. Tenéis como nosotros la energía de la juventud. $Y$ sois americanos como nosotros. Deberíamos dirigirnos más y más hacia vosotros." Las dos Américas unidas, la sajona y la ibera, pueden crear el futuro del espíritu, tienen capacidad para ello. América es el futuro de la cultura en un momento en que esta cultura se encuentra amenazada por las poderosas fuerzas del materialismo que tratan de destruirla. "Necesitamos uno del otro. Pero a fin de ayudarnos mutuamente, debemos aprender a ayudarnos a nosotros mismos, o sea a conocernos a nosotros mismos." Conociéndonos a nosotros mismos conoceremos también la esencia de otros hombres, lo que de común tenemos con ellos. Descubriendo nuestro ser, habremos descubierto elementos que son de América, "que armonizan con lo que otros hombres, en otras partes de América, igualmente empeñados en descubrirse a sí propios, están aprendiendo y necesitan".

Otro filósofo norteamericano, Filmer S. C. Northrop, se ha planteado también el problema de las relaciones de la América sajona con la América ibera. La segunda, como para Waldo Frank, representa el complemento de 
la primera porque encierra valores que la historia le ha permitido desarrollar, a diferencia de la América sajona que se ha visto obligada a seguir otro camino: ese camino de la técnica que le ha permitido expandirse y predominar en el mundo gracias a su poderosa fuerza económica. En su desarrollo, tanto la América sajona como la ibera han marchado unilateralmente. La ibera se ha inclinado hacia el mundo de los valores estéticos y religiosos, a diferencia de la sajona que se ha preocupado más por los valores científicos y técnicos. Northrop cree que podrá realizarse un intercambio de valores que permitirán, a la larga, la compenetración de ambas Américas. La América sajona necesita de los valores estéticos y religiosos tanto como la ibera de los científicos y técnicos. Es más, este intercambio podrá, a su vez, ser el punto de partida para una mayor compenetración entre los valores de la cultura occidental y los de la cultura oriental. Una filosofía americana que surgiese de la conjución de los valores de la cultura angloamericana y de los los de la cultura iberoamericana acabaría siendo una filosofía universal capaz de borrar las diferencias entre Oriente y Occidente, capaz de expresar la unidad del mundo. "Una filosofía y una cultura - dice Northrop- construidos sobre la correlación de los dos componentes eliminaría la contradicción de Occidente y el Oriente, de Rusia y de las democracias liberales, de la cultura de los Estados Unidos y de la hispanoamericana. Toda cultura y sociedad gana muchísimo y se enriquece a sí misma al ser suplementada con valores culturales diferentes armónicamente difundidos. Asi, por ejemplo, Occidente puede enriquecerse enormemente al tomar del Oriente el componente estético tal como aparece en las religiones, en el arte, en el espíritu de tolerancia orientales... Por otra parte el Oriente puede beneficiarse inconmensurablemente aceptando del Occidente la ciencia, la tecnología y otros valores teóricos de la cultura predominantemente cientifica de Occidente."

Esta misma preocupación complementaria por lo que respecta a los elementos culturales que contienen una y otra América la hace Northrop igualmente patente en su tesis sobre la necesidad de una filosofía que englobe las dos actitudes del hombre en América. En su opinión, debe complementarse el punto de vista del pragmatismo anglosajón y el de la filosofía existencial europea con el punto de vista individualista y estético iberoamericano. "La parte angloamericana del mundo panamericano - dice- y la tradicional ortodoxia del mundo europeo, con su reducción a los valores culturales hacia el peso empírico-pragmático de lo racional, o a un análisis lógico de lo consistentemente racional, deben tomar muy en cuenta la verdad y el valor del individualismo existencial español, basado en la imaginación y en la pasión, conservando también aquellas otras filosofias de Panamérica y Europa que fundamentan las instituciones culturales y la conducta moral, tanto en la esencia como en la existencia." Debe encontrarse, agrega, una nueva formulación del contenido del hombre, una nueva filosofía de las esencias que 
deberá combinarse con la filosofía de la existencia. Pero, a su vez, esta "filosofía debe enriquecerse... con la inclusión del indeterminado y existencial continuum estético, que es el factor común en la civilización indigena panamericana y en la civilización oriental".

\section{IV}

Ahora bien, ¿cómo ha reaccionado el iberoamericano frente al regateo que se hace de su humanidad y su posibilidad para la cultura; o frente a las demandas de colaboración como las que le hacen los angloamericanos? Reacciona, como ya se indicó al principio de este trabajo, mostrando a los enjuiciadores y demandantes su capacidad para lo que se le niega o para lo que se le solicita. Ante estos juicios y estas demandas reacciona realizando esa serie de trabajos que tienen como meta hacer conscientes sus posibilidades como hombre en general y como hombre de cultura en particular. El iberoamericano, en estos estudios, va tomando conciencia de su ser, de un ser que no es sino el del hombre, el de cualquier hombre en una determinada situación. Armado de este conocimiento de sí mismo, de su innegable humanidad, puede ya decir al mundo usando las palabras que pronunciaba Alfonso Reyes ante un selecto grupo de pensadores de renombre universal: "Hace tiempo que entre España y nosotros existe un sentimiento de nivelación y dignidad. Y ahora digo ante el tribunal de pensadores internacionales que me escucha: reconocednos el derecho a la ciudadanía universal que ya hemos conquistado. Hemos alcanzado la mayoría de edad. Muy pronto os habituaréis a contar con nosotros."

En esa búsqueda que tiende a la toma de conciencia de la humanidad, puesta en duda, del americano y de sus posibilidades para participar en una tarea que es común a todos los hombres, son ya muchos los filósofos, historiadores, sociólogos, psicólogos y literatos en la América ibera que participan o han participado ofreciendo sugestivas interpretaciones de carácter general como los ya citados Alfonso Reyes y José Vasconcelos, a los que podríamos unir los nombres de Pedro Henríquez Ureña y Felix Schwartzmann. Otros han enfocado el problema desde un punto de vista regional, como Ezequiel Martínez Estrada, Arturo Ardao, Joao Cruz Costa, Gilberto Freire, Mariano Picón Salas, Alberto Zum Felde, Francisco Romero, Be. Sanin Cano, Pareja Diezcanseco, Aurelio y Francisco Miró Quesada, Medardo Vitier, Aníbal Sánchez Reulet, José Gaos, Viana Moog, Sergio Buarque de Holanda, Daniel Cosío Villegas, Samuel Ramos, Lewis Hanke y otros muchos más en ambas Américas. Voluminoso sería el análisis de todas estas aportaciones en las que la meta es siempre mostrar las calidades humanas del hombre en América y su capacidad para participar en la cultura universal.

LEOPOLDO ZEA 